\title{
Conversion of biochar to sulfonated solid acid catalysts for spiramycin hydrolysis: Insights into the sulfonation process
}

Qianqian Xie ${ }^{1}$, Xiao Yang ${ }^{2}$, Kangning Xu${ }^{1}$, Zheng Chen ${ }^{1}$, Binoy Sarkar ${ }^{3}$, Xiaomin Dou ${ }^{*}$

${ }^{1}$ College of Environmental Science and Engineering, Beijing Forestry University, Beijing 100083, P.R.

China

${ }^{2}$ Key Laboratory of Land Surface Pattern and Simulation, Institute of Geographic Sciences and Natural

Resources Research, Chinese Academy of Sciences, Beijing 100101, China

${ }^{3}$ Lancaster Environment Centre, Lancaster University, Lancaster, LA1 4YQ, United Kingdom

*Corresponding author: Xiaomin Dou (douxiaomin@bjfu.edu.cn)

College of Environmental Science and Engineering, Beijing Forestry University, Beijing 100083, PR China 


\section{Highlights:}

>Methods suggested to convert biochar to solid acids towards spiramycin hydrolysis.

$>$ Biochar with high $\mathrm{O} / \mathrm{C}$ and $\mathrm{N}$ contents and less graphitic features are preferred.

$>$ Biochar hydrothermally treated using $\mathrm{ClSO}_{3} \mathrm{H}$ achieved the highest total acidity.

$>$ Total acidity, $\mathrm{SO}_{3} \mathrm{H}$ and $\mathrm{COOH}$ dominantly contributed to spiramycin hydrolysis.

$>$ A promising work on using sulfonated biochar as catalysts for antibiotic remediation. 


\begin{abstract}
Biochar has been recognized as a sustainable platform for developing functional materials including catalysts. This work demonstrated a method of converting biochar to sulfonated solid-acid catalysts, and the effectiveness of the catalysts for spiramycin hydrolysis was examined. Two biochar samples ( $\mathrm{H}$ and $\mathrm{X}$ ) were sulfonated with three reagents (concentrated $\mathrm{H}_{2} \mathrm{SO}_{4}, \mathrm{ClSO}_{3} \mathrm{H}$ and $p$-toluenesulfonic acid $(\mathrm{TsOH}))$ under hydrothermal, simple heating, ambient temperature, and $\mathrm{CHCl}_{3}$-assisted treatments. The effect of elemental compositions and structural characteristics of the feeding materials $(\mathrm{H}$ and $\mathrm{X})$ on the acidic properties of the sulfonated biochars were investigated. The results showed that the sulfonation ability of the three reagents was in the order of $\mathrm{ClSO}_{3} \mathrm{H}>\mathrm{H}_{2} \mathrm{SO}_{4}>\mathrm{TsOH}$, while hydrothermal treatment provided the highest total acidity, and largest amount of acidic groups (e.g., $\mathrm{SO}_{3} \mathrm{H}, \mathrm{COOH}$ and $\left.\mathrm{Ar}-\mathrm{OH}\right)$. Biochar $\mathrm{X}$ with higher $\mathrm{O} / \mathrm{C}$ and $\mathrm{N}$ contents, and less graphitic features showed superior acidic properties than biochar $\mathrm{H}$ under all the employed treatments. The hydrolytic efficiencies of the sulfonated biochars under $200 \mathrm{~W}$ of microwave irradiation increased with increasing total acidity, and the amount of $\mathrm{SO}_{3} \mathrm{H}$ and $\mathrm{COOH}$ groups. After sulfonation, the $\mathrm{O} / \mathrm{C}$ of biochars increased, while H/C decreased, and the aromatic and graphitic features did not change. The electromagnetic energy absorbed by the sulfonated biochars did not notably contribute to spiramycin hydrolysis. Thus, this work demonstrated an effective and promising method for maneuvering biocharbased functional solid-acid catalysts for antibiotic remediation in contaminated water.
\end{abstract}

Keywords: biochar, sulfonation, solid acid catalysts, spiramycin hydrolysis, antibiotic remediation 


\section{Introduction}

Biochar is considered as a versatile carbon platform for developing functional materials with multidisciplinary applications. Activation, amination, oxidation, recombination and sulfonation are the principle functionalization processes with products used for energy storage, pollutant mitigation, biorefinery, soil remediation and solid acid catalyzation (Liu et al., 2015). Sulfonation is one of the most efficient routes for biomass-upgrading, biofuel production, and carbon-based catalyst (e.g., solid acids) synthesis (Cao et al., 2017). Sulfonic acid group ( $\left.\mathrm{SOH}_{3}\right)$-bearing solid acids synthesized via sulfonation process are one of the main avenues for solid acid catalyst production (Gupta and Paul, 2014).

Biochar-based solid acid catalysts can be synthesized directly from biomass sulfonation or pyrolysis/hydrothermal treatment combined with subsequent sulfonation, which refer to the one-pot and post-synthetic sulfonation methods, respectively. The former involves one-pot reactions of biomass dehydration, carbonation and sulfonation simultaneously within one reaction vessel in a green fashion, while the latter has the advantages of adjusting the carbonization and sulfonation conditions simultaneously and tuning the acidic properties of yielded solid acids consequently. These biocharbased solid acids have been used in various applications including oleic acid esterification, bio-oil production, heterocycle compounds synthesis, cellobiose hydrolysis, sugar hydrolysis and dehydration (Gupta and Paul, 2014; Kitano et al., 2009; Lam and Luong, 2014). Hydrolysis of carbohydrates (such as starch or cellulose) to their monosaccharide components can be achieved through catalytically breaking the glycoside bonds by biochar-based solid acids (Kitano et al., 2009).

Hydrolysis is a significant degradation pathway for widely used antibiotics such as macrolide, 
aminoglycoside and $\beta$-lactam in the environment (Mitchell et al., 2015). Hydrolytic breaking of functional groups or structural linkages of these antibiotics, such as glycosidic bonds, lactone bonds or amido bonds, can decrease the bacterial-resistant activities of the parent compounds (Chen et al., 2019b). For spiramycin, the mycaminose, forosamine, and mycarose moieties connected to the 16member ring lactone via glycosidic bonds are the antibiotic-active functional groups (Hansen et al., 2002). Hydrolytically breaking the glycosidic bonds will remove one or more of these deoxyhexoses, which can inevitably decrease or even eliminate the antibacterial potency of spiramycin (Chen et al., 2019b; Yang et al., 2019). After hydrolytic pretreatment, the wastewater can be further treated using biological treatment processes without concerning the proliferation of resistant-bacteria and genes. Thus, the hydrolysis method is rather selective compared to advanced oxidation processes (Katritzky et al., 2009), including biochar-based catalysts facilitated oxidations (Lee et al., 2017), which work well but do not fully mineralize organic matters including spiramycin. Considering the effectiveness of breaking glycosidic bonds in intractable sugars (e.g., cellulose) (Lam and Luong, 2014; Suganuma et al., 2008), biochar-based solid acids bearing $\mathrm{SO}_{3} \mathrm{H}$ groups have high potential for pretreating macrolides (e.g., spiramycin) in production wastewater through hydrolytically cleaving the same kind of bonds. Results on cellulose hydrolysis indicated that the amount of acidic groups in sulfonated char and diversity of acidic sites (e.g., $\mathrm{SOH}_{3}, \mathrm{COOH}, \mathrm{ArOH}$ and $\mathrm{OH}$ sites) evidently affect the hydrolytic efficiencies (Fukuhara et al., 2011; Kitano et al., 2009; Lam and Luong, 2014). Thus, the efficacy of glycosidic bond hydrolysis in antibiotics, and the governing factors are worthy to investigate thoroughly.

For converting biomass or biochar to sulfonated solid acids, commonly used sulfonation reagents include concentrated sulfuric acid, oleum, gaseous sulfur trioxide, chlorosulfonic acid, sulfamic acid, 
sulfosalicylic acid and p-toluenesulfonic acid (Aro and Fatehi, 2017; Chen et al., 2019a; Zhang et al., 2010). The first four chemicals are widely used sulfonation reagents in industry, and the first two are more intensive than others (Foster, 1997). Concentrated sulfuric acid $\left(\mathrm{H}_{2} \mathrm{SO}_{4} ; 98 \% \sim 100 \%\right)$ is reactive towards numerous organic feedstocks, and the sulfonation reaction is usually mild with few side reactions and less byproducts. Excessive use of $\mathrm{H}_{2} \mathrm{SO}_{4}$ can decrease the viscosity of the reaction solution, thus enhancing the heat transfer inside the solution. The drawback is that the acid concentration may drop by $10 \%$ approximately because equal moles of water relative to $\mathrm{H}_{2} \mathrm{SO}_{4}$ may form during the reaction, and the resultant water may dilute the acid (Foster, 1997). Oleum has a higher reactivity compared with concentrated $\mathrm{H}_{2} \mathrm{SO}_{4}$ towards relatively inert aromatic compounds, but the oleum sulfonation process produces a large by-product stream of either $\mathrm{HCl}$ or $\mathrm{H}_{2} \mathrm{SO}_{4}$. Consequently, the recovery of byproducts and disposal of the solid wastes needing specialized equipment become costly (Foster, 1997). Chlorosulfonic acid is of particular value when used in excess for the direct chlorosulfonation of a wide range of organic compounds (Cremlyn, 2002). Another frequently used reagent, $p$-toluenesulfonic acid, a strong organic acid with a $\mathrm{pK}_{\mathrm{a}}$ value of -2.8 , has been employed both as a sulfonating agent and an acidic catalyst in converting biomass to sulfonated char under designed reaction conditions (Kang et al., 2017; Zhang et al., 2010). Amorphous carbon-bearing $\mathrm{SO}_{3} \mathrm{H}$, $\mathrm{COOH}$ and $\mathrm{OH}$ groups, prepared through direct sulfonation of incompletely carbonized organic matter, demonstrated excellent insoluble Brønsted acid activity for various acid-catalyzed reactions (e.g., cellobiose hydrolyses). Higher reactivity and efficacy were achieved with the above acid catalysts for crystalline cellulose, glucose and cellobiose hydrolyses than niobic acid, H-mordenite and resins (e.g., Amberlyst-15 and Nafion NR50) (Fukuhara et al., 2011; Kitano et al., 2009; Suganuma et al., 2008).

Systematic investigations concerning the effects of various sulfonation reagents (e.g., concentrated 
$\mathrm{H}_{2} \mathrm{SO}_{4}$, chlorosulfonic acid and $p$-toluenesulfonic acid) and reaction procedures on the acidic properties of the products are urgently needed. Furthermore, various biomass (e.g. sawdust and grass) and biochar were used as the starting materials for sulfonation, but the effects of the precursor characteristics on the acidic properties of the products remain unclear (Cao et al., 2017; Liu et al., 2015; Xiong et al., 2018). The functional relationship between properties of sulfonated biochar and their antibiotic hydrolysis performances can be complex under multiple interplaying factors such as raw biochar characteristics, sulfonation reagent type and synthesis procedure employed. In addition, a thermal condition can facilitate reaction and has showed promising results on promoting the hydrolysis of spiramycin by solid acids (Chen et al., 2019b; Yu et al., 2019). Acid-thermal coupled hydrolysis reactions using sulfonated biochar require comprehensive studies for their use in environmental antibiotic mitigation (Chen et al., 2019b; Yu et al., 2019).

In this work, two biochar samples were converted to solid acid catalysts for spiramycin (a representative lactone antibiotic) mitigation through five sulfonation strategies. Three sulfonation reagents under multiple sulfonation procedures were evaluated and compared. The efficiency of spiramycin hydrolysis using the sulfonated biochars under microwave irradiation was examined. The main objectives are to: (1) identify the most suitable sulfonation reagent and procedure to convert biochar to sulfonic acid group $\left(\mathrm{SOH}_{3}\right)$-bearing solid acids, (2) reveal the effect of biochar properties on the features of the synthesized solid acids, and (3) understand the relationship between solid acid properties and their hydrolytic performances for spiramycin mitigation in aqueous media. 


\section{Materials and methods}

\subsection{Materials}

Two commercial biochars prepared from Ageratina adenophora (grass) and Quercus dentata (oak wood) at $400{ }^{\circ} \mathrm{C}$ were procured from Xiyu Biotech Co., Ltd. (Panzhihua, Sichuan Province, China) and Gangwon Charmsoot Company (Hoengseong-gun, Gangwon Province, South Korea), respectively. They were labeled as $\mathrm{X}$ and $\mathrm{H}$, respectively. The raw biochars were milled, and sieved through a 0.25 mm mesh before sulfonation. Spiramycin (98\%, HPLC standard) was purchased from Dr. Ehrenstorfer GmbH (Germany). Chloroform, concentrated $\mathrm{H}_{2} \mathrm{SO}_{4}$ (98\%), chlorosulfonic acid $\left(\mathrm{ClSO}_{3} \mathrm{H}\right.$; 99.5\%), and $p$-toluenesulfonic (TsOH, AR) were purchased from Sigma Aldrich (USA). Ultra-pure water (18.2 $\mathrm{M} \Omega \cdot \mathrm{cm}$ ) was obtained using a Milli-Q purification equipment (Millipore, USA).

\subsection{Sulfonated biochar preparation and characterization}

Three sulfonation reagents including concentrated $\mathrm{H}_{2} \mathrm{SO}_{4}, \mathrm{ClSO}_{3} \mathrm{H}$, and $\mathrm{TsOH}$ were used to convert the two biochar samples to solid acids following five sulfonation procedures. The reaction conditions are summarized in Table 1. Briefly, the solid-to-acid solution ratio was $20 \mathrm{~mL}$-acid/g-biochar for concentrated $\mathrm{H}_{2} \mathrm{SO}_{4}$ and $\mathrm{ClSO}_{3} \mathrm{H}$ in each treatment. The dosage of $\mathrm{TsOH}(53.52 \mathrm{~g})$ was determined equivalently to the mole numbers of $\mathrm{SO}_{3} \mathrm{H}$ contained in $20 \mathrm{~mL}$ of concentrated $\mathrm{ClSO}_{3} \mathrm{H}$. After treatment under given conditions (Table 1), the solutions were added dropwise into $1000 \mathrm{~mL}$ of deionized water, and stirred intensively. The diluted suspension was vacuum filtered, and the paste was retained on a filter paper. Then, it was rinsed twice using $300 \mathrm{~mL}$ of hot water at $80{ }^{\circ} \mathrm{C}$ each time. Finally, the products were transferred, and oven-dried at $120{ }^{\circ} \mathrm{C}$ for $12 \mathrm{~h}$. After drying, the products 
were stored in capped glass vessels, and put into a desiccator for further use.

The specific surface area (SSA), pore volume and pore size distribution were measured by multipoint $\mathrm{N}_{2}$ adsorption-desorption method on a miniX equipment (Microtrac, Japan). Acidic groups on the surface were determined by the Boehm titration method. Ultimate analyses were performed on a Vario EL cube elemental analyzer (Elementar, Germany). X-ray photoelectron spectra (XPS) were recorded on a hemispherical energy analyzer (PHI, USA) with an Al- $k_{\alpha}$ anode radiation source as the excitation source. The high-resolution transmission electron microscope (HR-TEM) images were acquired using a Titan ${ }^{\mathrm{TM}}$ G2 $60-300$ double aberration-corrected spectrometer (FEI, USA), and the electron energy loss spectra (EELS) were obtained using a line-scan mode on the EELS spectrometer associated with the TEM. Raman spectra were collected at room temperature with a SENTERRA II spectrometer (Bruker, German), equipped with a thermoelectrically cooled charge-coupled device (CCD), and a laser energy of $532 \mathrm{~nm}$ was used as the excitation source. The ${ }^{13} \mathrm{C}$ solid MAS NMR spectra were collected on a Bruker ARX400 spectrometer at $400 \mathrm{MHz}$. The microwave-absorption behavior of biochar before and after adsorption were measured on a Keysight PNA-N5244A vector network analyzer (Agilent, USA) according to a published method (Li et al., 2020).

\subsection{Spiramycin hydrolyses by solid acids under microwave irradiation}

The hydrolysis reactions were performed in an ANKS-HX-3 frequency modulation-tuned microwave equipment working at $2450 \mathrm{MHz}$ (Ennix, Qingdao, China), with the output power continuously adjustable from $0-1200 \mathrm{~W}$, which is different with the pulse width modulation-tuned domestic microwave. The initial concentration of spiramycin was $40 \mathrm{mg} / \mathrm{L}$, and the initial solution $\mathrm{pH}$ was ca. 6.85. A fixed dosage of sulfonated biochar $(1.0 \mathrm{~g} / \mathrm{L})$ was added to each $100 \mathrm{~mL}$ of sealed glass 
bottle containing $50 \mathrm{~mL}$ of spiramycin solution. The solution $\mathrm{pH}$ dropped to ca. 3.0 after addition of sulfonated biochar. Then, the solutions were separately irradiated at $200 \mathrm{~W}$ under $50 \mathrm{rpm}$ agitation for $10 \mathrm{~min}$, and the temperature was increased with time, and reaching finally up to $90-100{ }^{\circ} \mathrm{C}$. During the process, the reacted solutions were sampled at pre-set intervals, filtered through a $0.22-\mu \mathrm{m}$ glass fiber membrane, and stored at $-4{ }^{\circ} \mathrm{C}$ immediately. All samples were analyzed within $36 \mathrm{~h}$.

The concentration of spiramycin was determined using an Agilent 1260 high-performance liquid chromatography (HPLC) (Agilent, CA, USA) equipped with a Shimadzu WondaSil C18-WR column, and a diode array detector set at $232 \mathrm{~nm}$. The mobile phase consisted of a mixture of $50 \mathrm{mM}$ ammonium acetate solution and acetonitrile $(63: 37, \mathrm{v} / \mathrm{v})$, and was run at a flow rate of $1.0 \mathrm{~mL} / \mathrm{min}$. The column temperature was set to $30{ }^{\circ} \mathrm{C}$, and the chromatographic detection time was $8 \mathrm{~min}$. In this work, parallel experiments were conducted, and each sample was measured three times. Average values were reported.

\section{Results and discussion}

\subsection{Properties of feeding biochar materials}

Elemental analyses indicated that biochar $\mathrm{X}$ had higher $\mathrm{O} / \mathrm{C}$ and $\mathrm{N}$ contents than biochar $\mathrm{H}$ (Table 2). The Raman shifts are presented in Fig. 1(a). Moderately broadened D peak and sharp G peak appeared at Raman shifts of 1360 and $1590 \mathrm{~cm}^{-1}$, respectively, while very weak and broad 2D peaks were observed at ca. $2700 \mathrm{~cm}^{-1}$. The D band is usually associated with structural defects and disorder, and $\mathrm{G}$ band is associated with the $s p^{2}$ graphitic domains (Ferrari, 2007). A larger intensity ratio $\left(I_{\mathrm{D}} / I_{\mathrm{G}}\right)$ of $\mathrm{D}$ and $\mathrm{G}$ bands for $\mathrm{X}(2.63)$ than $\mathrm{H}$ (2.52) represents a higher structure disorder of the former biochar. 
The weakened or even absence of 2D peak implied low $s p^{3}$ amorphous carbon, or scattered and unordered domains composed of mainly $s p^{2}$ nanocrystalline graphite (Ferrari, 2007; Wollbrink et al., 2016). The ${ }^{13} \mathrm{C}$ solid MAS NMR spectra (Fig. 1b) indicated aromatic characteristics of the biochar samples with low contents of aliphatic carbon. A strong signal in the aromatic carbon-assigned chemical shift region (100-250 ppm) appeared, while only weak chemical shift signals at ca. $52 \mathrm{ppm}$ were observed (Fig. 1b). The signal at ca. $52 \mathrm{ppm}$ was likely due to the uncharred cellulose residuals remaining in both the samples (Liang et al., 2018; Rutherford et al., 2012).

The hybridization states of the carbon atoms in the sulfonated biochar were determined by using both EELS (Fig. 2a-d) and XPS (Fig. 2e-f) investigations. The line-scan positions were marked on the HR-TEM images, and the resolved carbon $K$-edge high-loss spectra were presented in Fig. 2c-d. A disordered nature was presented in the HR-TEM images. The $K$-edge spectra were decomposed to three Gaussian components, where G1, G2 and G3 at $285.0 \mathrm{eV}, 292.0 \mathrm{eV}$ and $298.0 \mathrm{eV}$, were due to the electronic transition from carbon $1 \mathrm{~s}$ to $\mathrm{C}=\mathrm{C} \pi^{*}$ orbital, $\mathrm{C}-\mathrm{C} \sigma^{*}$ orbital, and $\mathrm{C}=\mathrm{C} \sigma^{*}$ orbital, respectively (Yoo et al., 2018a; Yoo et al., 2018b). The content of $s p^{2}$ binding could be determined by a relative value between the sample carbon $1 \mathrm{~s}$ to $\pi^{*}$ transition peak area ratio, and that of graphite defined by Eq. 1 (Yoo et al., 2018b):

$$
\begin{aligned}
\operatorname{sp}^{2} \text { content } & =\frac{\left[\frac{\operatorname{area}(\pi *)}{\operatorname{area}(\pi *+\sigma *)}\right]_{\text {Sample }}}{\left[\frac{\operatorname{area}(\pi *)}{\operatorname{area}(\pi *+\sigma *)}\right]_{\text {Graphite,reference }}} \\
& =\frac{\left[\frac{G 1}{G 1+G 2+G 3}\right]_{\text {Sample }}}{\left[\frac{G 1}{G 1+G 2+G 3}\right]_{\text {Graphite,reference }}}
\end{aligned}
$$

(Eq. 1) 


$$
\begin{aligned}
\frac{s p_{H}^{2}}{s p_{X}^{2}} & =\frac{\left[\frac{\operatorname{area}(\pi *)}{\operatorname{area}(\pi *+\sigma *)}\right]_{H}}{\left[\frac{\operatorname{area}(\pi *)}{\operatorname{area}(\pi *+\sigma *)}\right]_{X}} \\
& =\frac{\left[\frac{G 1}{G 1+G 2+G 3}\right]_{H}}{\left[\frac{G 1}{G 1+G 2+G 3}\right]_{X}}
\end{aligned}
$$

The $s p^{2}$ ratio of sample $\mathrm{H}$ to $\mathrm{X}$ was determined to be 1.07 by directly comparing the sample H's carbon $1 \mathrm{~s}$ to $\pi^{*}$ transition peak area ratio with that of $\mathrm{X}$, without counting graphite, as defined by Eq. 2 . Further, the $s p^{2}$ and $s p^{3}$ contents were determined by the area ratios of deconvoluted XPS C1s component (Fig. 2e-f), according to Wollbrink et al. (Wollbrink et al., 2016). The determined contents of $s p^{2}$ and $s p^{3}$ were $68.84 \%$ and $31.16 \%$, and $60.32 \%$ and $39.68 \%$ for sample $\mathrm{H}$ and $\mathrm{X}$, respectively. The relative $s p^{2}$ content of $\mathrm{H}$ to $\mathrm{X}$ was 1.14 , which was consistent with the EELS results. These results indicated that sample $H$ was more graphitic than $\mathrm{X}$. During pyrolysis, the cellulose and lignin branches were decomposed, and the aromatic backbone was left. Meanwhile, disordered carbon clusters and a few graphitic domains were developed. Accordingly, the $s p^{3}$ contents contributed from aliphatic carbon (e.g., cellulose and hemicellulose) were decreased, and the $s p^{2}$ contents from aromatic carbon (e.g., lignin residual, condensed ring and graphite) were increased (Park et al., 2019; Wiedemeier et al., 2015). The pyrolysis temperature of $\mathrm{H}$ was roughly $50{ }^{\circ} \mathrm{C}$ higher than $\mathrm{X}$, which likely resulted more graphitic domains in sample $\mathrm{H}$ than $\mathrm{X}$. In addition, the difference in lignin contents of the originating biomasses might also affect the $s p^{2}$ contents in $\mathrm{H}$ and $\mathrm{X}$.

\subsection{Effect of sulfonation conditions}

Total acidities and contents of $\mathrm{SO}_{3} \mathrm{H}, \mathrm{COOH}, \mathrm{Ar}-\mathrm{OH}$ and lactones of the sulfonated biochars were provided in Fig. 3. The sulfonation conditions leading to high acidity followed an order: $\mathrm{ClSO}_{3} \mathrm{H}$ 
hydrothermal treatment $>\mathrm{H}_{2} \mathrm{SO}_{4}$ hydrothermal treatment $>\mathrm{ClSO}_{3} \mathrm{H}$ with $\mathrm{CHCl}_{3}$ at $25{ }^{\circ} \mathrm{C}>\mathrm{ClSO}_{3} \mathrm{H}$ at $25{ }^{\circ} \mathrm{C}>\mathrm{TsOH}$ hydrothermal treatment. Hydrothermal treatment was the most effective way to convert biochar to solid acids for both sample $\mathrm{H}$ and $\mathrm{X}$. The acidification efficiency of the three reagents during the sulfonation process followed the order: $\mathrm{ClSO}_{3} \mathrm{H}>\mathrm{H}_{2} \mathrm{SO}_{4}>\mathrm{TsOH}$, regardless of the properties of feeding biochar. Hydrothermal treatment using $\mathrm{ClSO}_{3} \mathrm{H}$ was superior to $\mathrm{ClSO}_{3} \mathrm{H}$ with $\mathrm{CHCl}_{3}$ at $25{ }^{\circ} \mathrm{C}$, and was far better than $\mathrm{ClSO}_{3} \mathrm{H}$ alone at $25{ }^{\circ} \mathrm{C}$. The raising temperature and pressure enhanced the reactivity of $\mathrm{ClSO}_{3} \mathrm{H}$, and the solvent $\mathrm{CHCl}_{3}$ also mediated the sulfonation process. As an excellent polar solvent, $\mathrm{CHCl}_{3}$ likely promoted the dispersion of $\mathrm{ClSO}_{3} \mathrm{H}$, and facilitated the interface reaction (Katritzky et al., 2009).

Functional groups such as $\mathrm{SO}_{3} \mathrm{H}, \mathrm{COOH}, \mathrm{Ar}-\mathrm{OH}$ and lactones were observed on the sulfonated biochar surfaces, and $\mathrm{SO}_{3} \mathrm{H}$ was the most abundant active sites on all the sulfonated biochars (Fig. 3a). The $\mathrm{SO}_{3} \mathrm{H}$ contents were positively correlated with the $\mathrm{O} / \mathrm{C}$ and $\mathrm{S} / \mathrm{C}$ ratios of the sulfonated biochar (Fig. 3b-c), while they were negatively correlated with the H/C ratios of the sulfonated X sample (Fig. 3d). A higher $\mathrm{S} / \mathrm{C}$ ratio was observed for $\mathrm{X}$ than $\mathrm{H}$ for each treatment (Fig. 3b), which was consistent with the $\mathrm{SO}_{3} \mathrm{H}$ acidity results from titration (Fig. 3a). After sulfonation, an increase in $\mathrm{O} / \mathrm{C}$, and a decrease in $\mathrm{H} / \mathrm{C}$ were observed, because the oxygen-abundant $\mathrm{SO}_{3} \mathrm{H}$ group was introduced on the surface, and a portion of $\mathrm{H}$ atoms were replaced. Other features such as the crystal structures (Fig. S1), structural defects and disorders (Fig. S2), and aromatic characteristics (Fig. S3) did not significantly change in the sulfonated solid acids in comparison to the pristine biochars.

\subsection{Correlations between surface/bulk properties and hydrolytic performances}

The hydrolytic performances of the sulfonated biochars toward spiramycin were provided in Fig. 4a, and the kinetic fitting curves using the pseudo-first order model were given in Fig. 4b. The solution 
reached to $90-100{ }^{\circ} \mathrm{C}$ temperature just within 10 min under $200 \mathrm{~W}$ microwave irradiation. Sample SX2 obtained by hydrothermal treatment using $\mathrm{ClSO}_{3} \mathrm{H}$ showed the best performance for spiramycin mitigation, followed by sample SH2 with the same sulfonation procedure. The initial concentration of spiramycin (40 mg/L) decayed within $8 \mathrm{~min}$ by SX2, and the pseudo-first order kinetic rate constant was estimated to be $0.22 \mathrm{~min}^{-1}$. In addition, the serial SX samples presented better performances than the SH counterparts prepared under identical conditions (Fig. 4).

The relationship of hydrolytic efficiencies (represented by the observed kinetic constants) with total acidity and amounts of $-\mathrm{SO}_{3} \mathrm{H}, \mathrm{Ar}-\mathrm{OH}$ and lactic groups suggested that the surface acidic properties contributed to the hydrolysis reaction (Fig. 5, and Table S1). The hydrolytic efficiencies were well correlated with the total acidity $\left(\mathrm{R}^{2}=0.94\right.$ for SHs, and 0.86 for $\left.\mathrm{SXs}\right)$, amounts of $\mathrm{SO}_{3} \mathrm{H}\left(\mathrm{R}^{2}=0.99\right.$ for SHs, and 0.78 for SXs), Ar-OH ( $\mathrm{R}^{2}=0.98$ for SHs, and 0.92 for SXs) for all the sulfonated biochar, and $\mathrm{COOH}\left(\mathrm{R}^{2}=0.92\right.$ for SXs) for SXs serial samples, while no significant correlation was observed between the hydrolytic efficiencies and amounts of lactic groups. These results indicated that both $\mathrm{SO}_{3} \mathrm{H}$ and $\mathrm{Ar}-\mathrm{OH}$ served as the active sites contributing to the hydrolytic activities of SHs and SXs, and $\mathrm{COOH}$ also contributed to that of SXs. Other acidic groups such as lactic groups also contributed but not dominantly. The total organic carbon (TOC) concentrations in the hydrolyzed solutions dropped by $12.1 \%$ and $7.2 \%$ for SH2 and SX2, respectively (Fig. S4), which meant that only less than $12.1 \%$ spiramycin mitigation might have occurred due to adsorption. Evaporation might also be responsible for the elimination of spiramycin, but it was negligible and hard to quantitatively differentiate from the acid catalyst-mediated hydrolysis in this work. Further studies are needed to minimize the evaporation effects on spiramycin removal, i.e., by using enclosed pressure-resistant vessels designed for such reactions. 


\subsection{Scheme of sulfonation reactions and deprotonation process}

Typical biochar surface contained abundant functional groups (Fig. 6(a)), and had undefined structure. Sulfonation reactions induced by $\mathrm{ClSO}_{3} \mathrm{H}$ occurred at multiple sites. The most common reactions with phenol, and $\mathrm{O}$ and $\mathrm{N}$-contained heterocyclic rings (e.g., model furan, pyridine and thiazole molecules) were presented in Fig. 6a (Cremlyn, 2002; Katritzky et al., 2009). The sulfonation reactions were demonstrated using $\mathrm{ClSO}_{3} \mathrm{H}$ as a representative reagent. The reactions were also applicable to other sulfonation reagents such as concentrated $\mathrm{H}_{2} \mathrm{SO}_{4}$, but the reaction conditions and extent might have varied when sulfonating the biochars. Biochar X had higher contents of O (17.48\% vs. $10.80 \%)$ and $\mathrm{N}(1.16 \%$ vs. $0.34 \%)$ than biochar $\mathrm{H}$ (Table 2$)$. It supposed that a portion of $\mathrm{O}$ and $\mathrm{N}$ contained sites might inevitably take part in the sulfonation reactions with $\mathrm{ClSO}_{3} \mathrm{H}$, promoting the diversity of acidic groups, and thus enhanced the total acidity. Fig. $1 \mathrm{~b}$ revealed that most of the components were aromatic compounds. Some O atoms would be contained in phenol or alkylphenol groups. The adjacent and counterpoint $\mathrm{H}$ atom in phenols is easier to be replaced than $\mathrm{H}$ atom alone in benzene rings by $\mathrm{SO}_{3} \mathrm{H}$, since the sulfonation reaction is an electrophilic substitution process. Some $\mathrm{N}$ atom-contained heterocyclic structures like pyrrole could also facilitate the sulfonation reaction. As Fig. $1 \mathrm{~b}$ has revealed, most of the components are aromatic compounds. Some $\mathrm{O}$ atoms are possibly contained in phenols or alkylphenol structures of biochar. The adjacent and counterpoint $\mathrm{H}$ atom in phenols is easier to be replaced than $\mathrm{H}$ atom alone in benzene rings by $\mathrm{SO}_{3} \mathrm{H}$, since the sulfonation reaction is an electrophilic substitution process. Some $\mathrm{N}$ atom-contained heterocyclic structures like pyrrole can also facilitate the sulfonation reaction. The scheme in Fig. 6a provided clues on where sulfonation reactions occurred, but failed to include all possible $\mathrm{O}$ and $\mathrm{N}$-involved sites. The relative significances of reactions occurring at various sites warrant future investigations. In addition, the 
deprotonation reactions on the Brønsted sites showed that deprotonated $\mathrm{H}^{+}$was the active species for spiramycin hydrolysis, but these solid acids were far less risky and corrosive than mineral acids during handling, storage, transportation, and usage.

\subsection{Contribution of microwave absorption characteristics}

Increased solution temperature could accelerate the kinetics and enhance the hydrolytic breakage of glycosidic bonds in spiramycin. Under irradiation, biochar absorbed the microwave via a dielectric heating process, which facilitated the microwave to transfer energies to biochar with a consequential rise in temperature. The dielectric heating would involve the interactions of $\pi$-electrons within the aromatic structures of carbon materials (Menéndez et al., 2010; Zhao et al., 2018). This work hence measured the role of the microwave absorbing effect of sulfonated biochar. The relative loss $(R L)$ curves in the frequency $(f)$ range of $2.0-18.0 \mathrm{GHz}$, and the $2 \mathrm{D}$ contour plots of $R L v s . f$ plus depth $(d)$ for samples H, X, SH2 and SX2 were presented in Fig. 7. The microwave absorption ability was determined by the reflection loss (RL) which is a characteristic indicator of electromagnetic absorbing property. Since a frequency of $2.45 \mathrm{GHz}$ was used in this work, the RL values at $2.45 \mathrm{GHz}$ were compared. No obvious differences were found between SH2 and SX2, and between sample H and X. Therefore, the microwave absorption abilities of SH2 and SX2 were not correlated with their hydrolytic performances. These results indicated that the microwave absorbing ability of sulfonated biochar was not a governing factor contributing to their hydrolytic activities. In order to identify and ascertain the role of microwave absorption, a high-resolution radio-frequency analysis covering 2.45 $\mathrm{GHz}$ is needed in future studies.

\section{Conclusions}

This work presented an effective method of converting biochar to sulfonated solid-acid catalysts for 
spiramycin hydrolysis. Three sulfonating reagents including $\mathrm{ClSO}_{3} \mathrm{H}$, concentration $\mathrm{H}_{2} \mathrm{SO}_{4}$ and $\mathrm{TsOH}$ under multiple conditions were examined in converting two biochar samples ( $\mathrm{H}$ and $\mathrm{X})$ to sulfonated catalysts. $\mathrm{ClSO}_{3} \mathrm{H}$ was the most active reagent, and a hydrothermal treatment at $100{ }^{\circ} \mathrm{C}$ for $24 \mathrm{~h}$ was the most efficient condition. The reagent $\mathrm{ClSO}_{3} \mathrm{H}$ at ambient condition performed better than $\mathrm{TsOH}$ under $100{ }^{\circ} \mathrm{C}$ of hydrothermal treatment. The elemental composition and structure of the pristine biochars evidently influenced the acidic properties of sulfonated catalysts. High $\mathrm{O} / \mathrm{C}$, large $\mathrm{N}$ contents, and less graphitic features of the feeding biochar led to high total acidity and large amounts of $\mathrm{SOH}_{3}$ and Ar-OH groups in the sulfonated products, which were significantly positively correlated with their spiramycin hydrolytic performances. After sulfonation, the $\mathrm{O} / \mathrm{C}$ increased and $\mathrm{H} / \mathrm{C}$ decreased, and other features such as the aromatic and graphitic characteristics did not change significantly. The microwave absorption characteristics of the sulfonated biochar were not associated with their spiramycin hydrolysis abilities. In short, this work is an essential step in the development of effective sulfonation methods to obtain low-cost biochar-based solid-acid catalysts for the mitigation of antibiotic pollutants in the environment.

\section{Acknowledgements}

This work was supported by the National Natural Science Foundation of China (51978052), and the State Key Joint Laboratory of Environmental Simulation and Pollution (19K01ESPCR).

\section{References.}

Aro, T., Fatehi, P., 2017. Production and application of lignosulfonates and sulfonated lignin. ChemSusChem. 10, 18611877.

Cao, X., Sun, S., Sun, R., 2017. Application of biochar-based catalysts in biomass upgrading: a review. RSC Adv. 7, 48793 - 
48805 .

Chen, G., Wang, X., Jiang, Y., Mu, X., Liu, H., 2019a. Insights into deactivation mechanism of sulfonated carbonaceous solid acids probed by cellulose hydrolysis. Catal. Today. 319, 25-30.

Chen, Z., Dou, X., Zhang, Y., Yang, M., Wei, D., 2019b. Rapid thermal-acid hydrolysis of spiramycin by silicotungstic acid under microwave irradiation. Environ. Pollut. 249, 36-44.

Cremlyn, R. J. W., Chlorosulfonic acid : a versatile reagent. Royal Society of Chemistry, Cambridge, 2002.

Ferrari, A. C., 2007. Raman spectroscopy of graphene and graphite: Disorder, electron-phonon coupling, doping and nonadiabatic effects. Solid State Commun. 143, 47-57.

Foster, N. C., Sulfonation and sulfation processes. The Chemithon Corporation Seattle, WA, 1997.

Fukuhara, K., Nakajima, K., Kitano, M., Kato, H., Hayashi, S., Hara, M., 2011. Structure and catalysis of cellulose-derived amorphous carbon bearing $\mathrm{SO}_{3} \mathrm{H}$ groups. ChemSusChem. 4, 778-784.

Gupta, P., Paul, S., 2014. Solid acids: Green alternatives for acid catalysis. Catal. Today. 236, 153-170.

Hansen, J. L., Ippolito, J. A., Ban, N., Nissen, P., Moore, P. B., Steitz, T. A., 2002. The structures of four macrolide antibiotics bound to the large ribosomal subunit. Molecular Cell. 10, 117-128.

Kang, S., Zhang, G., Yang, X., Yin, H., Fu, X., Liao, J., Tu, J., Huang, X., Qin, F. G. F., Xu, Y., 2017. Effects of ptoluenesulfonic acid in the conversion of glucose for levulinic acid and sulfonated carbon production. Energy Fuels. 31, 2847-2854.

Katritzky, A. R., Kim, M. S., Fedoseyenko, D., Widyan, K., Siskin, M., Francisco, M., 2009. The sulfonation of aromatic and heteroaromatic polycyclic compounds. Tetrahedron. 65, 1111-1114.

Kitano, M., Yamaguchi, D., Suganuma, S., Nakajima, K., Kato, H., Hayashi, S., Hara, M., 2009. Adsorption-enhanced hydrolysis of $\beta$-1,4-glucan on graphene-based amorphous carbon bearing $\mathrm{SO}_{3} \mathrm{H}, \mathrm{COOH}$, and $\mathrm{OH}$ groups. Langmuir. $25,5068-5075$.

Lam, E., Luong, J. H. T., 2014. Carbon materials as catalyst supports and catalysts in the transformation of biomass to fuels and chemicals. ACS Catal. 4, 3393-3410.

Lee, J., Kim, K.-H., Kwon, E. E., 2017. Biochar as a catalyst. Renewable Sustainable Energy Rev. 77, 70-79.

Li, Q., Zhu, J., Wang, S., Huang, F., Liu, Q., Kong, X., 2020. Microwave absorption on a bare biomass derived holey silicahybridized carbon absorbent. Carbon. 161, 639-646.

Liang, J., Chen, J., Wu, S., Liu, C., Lei, M., 2018. Comprehensive insights into cellulose structure evolution via multiperspective analysis during a slow pyrolysis process. Sustainable Energy Fuels. 2, 1855-1862.

Liu, W.-J., Jiang, H., Yu, H.-Q., 2015. Development of biochar-based functional materials: Toward a sustainable platform carbon material. Chem. Rev. 115, 12251-12285.

Menéndez, J. A., Arenillas, A., Fidalgo, B., Fernández, Y., Zubizarreta, L., Calvo, E. G., Bermúdez, J. M., 2010. Microwave heating processes involving carbon materials. Fuel Process. Technol. 91, 1-8. 
Mitchell, S. M., Ullman, J. L., Teel, A. L., Watts, R. J., 2015. Hydrolysis of amphenicol and macrolide antibiotics: Chloramphenicol, florfenicol, spiramycin, and tylosin. Chemosphere. 134, 504-511.

Park, J., Yoo, S., Lim, K. H., Rojas, O. J., Hubbe, M. A., Park, S., 2019. Impact of oxidative carbonization on structure development of loblolly pine-derived biochar investigated by nuclear magnetic resonance spectroscopy and X-ray photoelectron spectroscopy. Diamond Relat. Mater. 96, 140-147.

Rutherford, D. W., Wershaw, R. L., Rostad, C. E., Kelly, C. N., 2012. Effect of formation conditions on biochars: Compositional and structural properties of cellulose, lignin, and pine biochars. Biomass Bioenergy. 46, 693-701.

Suganuma, S., Nakajima, K., Kitano, M., Yamaguchi, D., Kato, H., Hayashi, S., Hara, M., 2008. Hydrolysis of cellulose by amorphous carbon bearing $\mathrm{SO}_{3} \mathrm{H}, \mathrm{COOH}$, and $\mathrm{OH}$ groups. J. Am. Chem. Soc. 130, 12787-12793.

Wiedemeier, D. B., Abiven, S., Hockaday, W. C., Keiluweit, M., Kleber, M., Masiello, C. A., McBeath, A. V., Nico, P. S., Pyle, L. A., Schneider, M. P. W., Smernik, R. J., Wiesenberg, G. L. B., Schmidt, M. W. I., 2015. Aromaticity and degree of aromatic condensation of char. Org. Geochem. 78, 135-143.

Wollbrink, A., Volgmann, K., Koch, J., Kanthasamy, K., Tegenkamp, C., Li, Y., Richter, H., Kämnitz, S., Steinbach, F., Feldhoff, A., Caro, J., 2016. Amorphous, turbostratic and crystalline carbon membranes with hydrogen selectivity. Carbon. 106, 93-105.

Xiong, X., Yu, I. K. M., Chen, S. S., Tsang, D. C. W., Cao, L., Song, H., Kwon, E. E., Ok, Y. S., Zhang, S., Poon, C. S., 2018. Sulfonated biochar as acid catalyst for sugar hydrolysis and dehydration. Catal. Today. 314, 52-61.

Yang, W., Ok, Y. S., Dou, X., Zhang, Y., Yang, M., Wei, D., Xu, P., 2019. Effectively remediating spiramycin from production wastewater through hydrolyzing its functional groups using solid superacid TiO2/SO4. Environ. Res. 175, 393-401.

Yoo, S., Chung, C.-C., Kelley, S. S., Park, S., 2018a. Graphitization behavior of loblolly pine wood investigated by in situ high temperature X-ray diffraction. ACS Sustainable Chem. Eng. 6, 9113-9119.

Yoo, S., Kelley, S. S., Tilotta, D. C., Park, S., 2018b. Structural characterization of loblolly pine derived biochar by X-ray diffraction and electron energy loss spectroscopy. ACS Sustainable Chem. Eng. 6, 2621-2629.

Yu, I. K. M., Xiong, X., Tsang, D. C. W., Wang, L., Hunt, A. J., Song, H., Shang, J., Ok, Y. S., Poon, C. S., 2019. Aluminiumbiochar composites as sustainable heterogeneous catalysts for glucose isomerisation in a biorefinery. Green Chem. 21, 1267-1281.

Zhang, B., Ren, J., Liu, X., Guo, Y., Guo, Y., Lu, G., Wang, Y., 2010. Novel sulfonated carbonaceous materials from ptoluenesulfonic acid/glucose as a high-performance solid-acid catalyst. Catal. Commun. 11, 629-632.

Zhao, H.-B., Cheng, J.-B., Wang, Y.-Z., 2018. Biomass-derived Co@crystalline carbon@carbon aerogel composite with enhanced thermal stability and strong microwave absorption performance. J. Alloys Compd. 736, 71-79. 
Figures
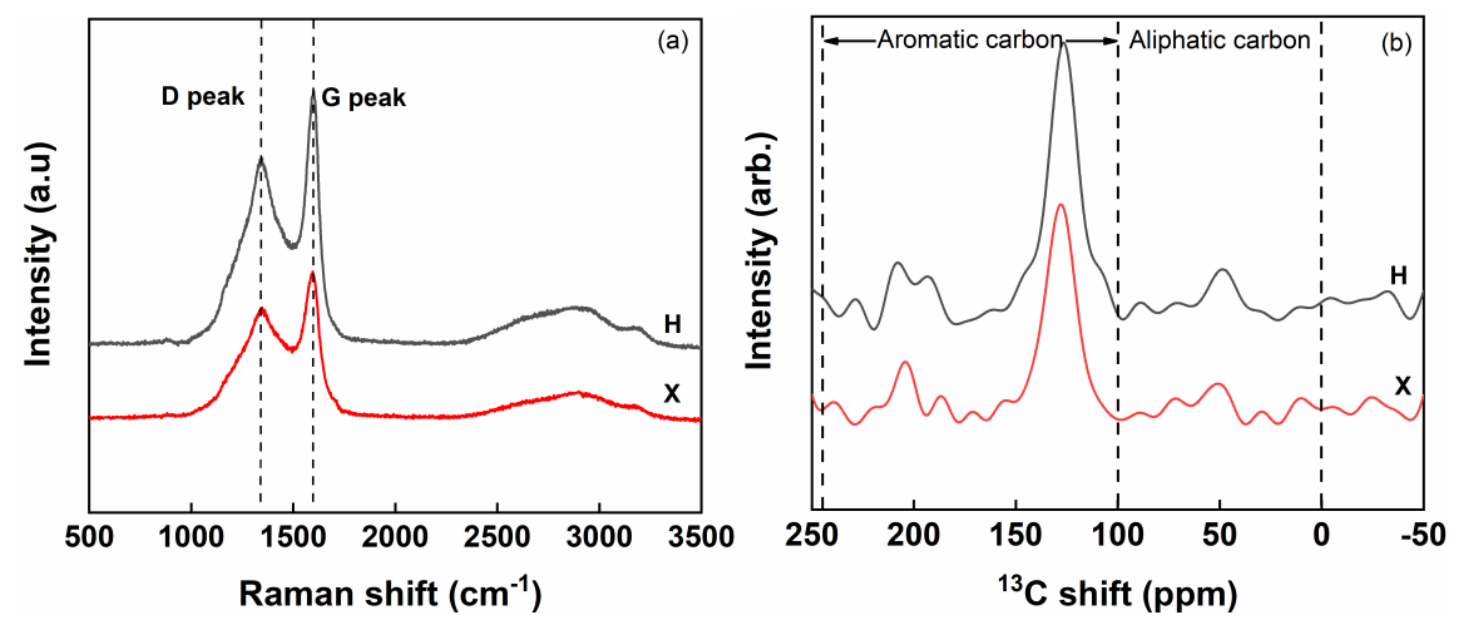

Fig. 1. (a) Raman spectra, and (b) ${ }^{13} \mathrm{C}$ MAS NMR chemical shifts of the pristine biochar $H$ and $X$. 

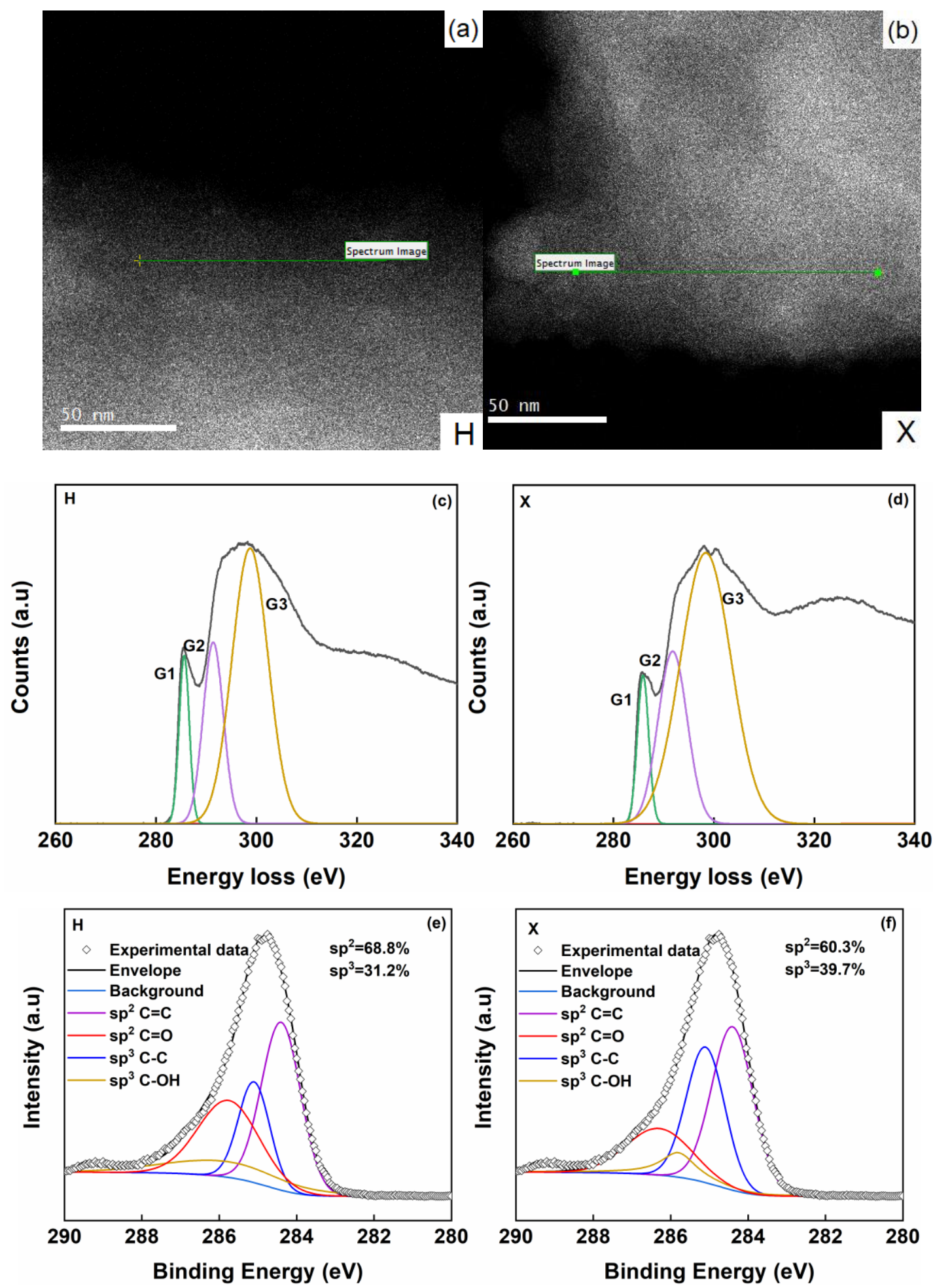

Fig. 2. (a-b) HRTEM, (c-d) EELS, and (e-f) XPS C1s spectra of the pristine biochar $H$ and X. 

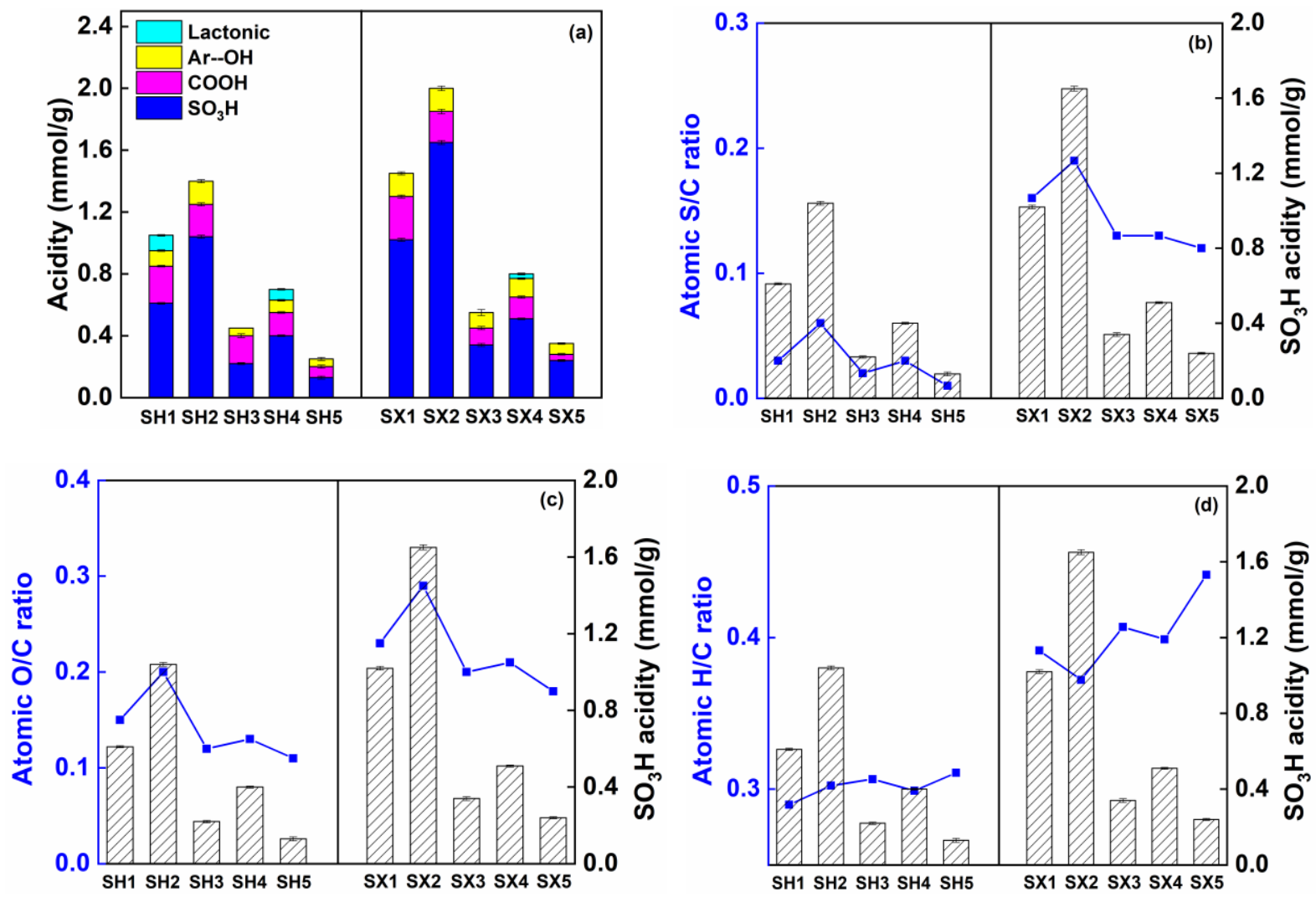

Fig. 3. (a) Total acidity and amount of each acidic group in the sulfonated biochar SH and SX at various sulfonation treatments. The relationships between the $\mathrm{SO}_{3} \mathrm{H}$ acidity and (b) atomic $\mathrm{O} / \mathrm{C}$ ratio, (c) atomic S/C ratio, and (d) atomic $\mathrm{H} / \mathrm{C}$ ratio. 

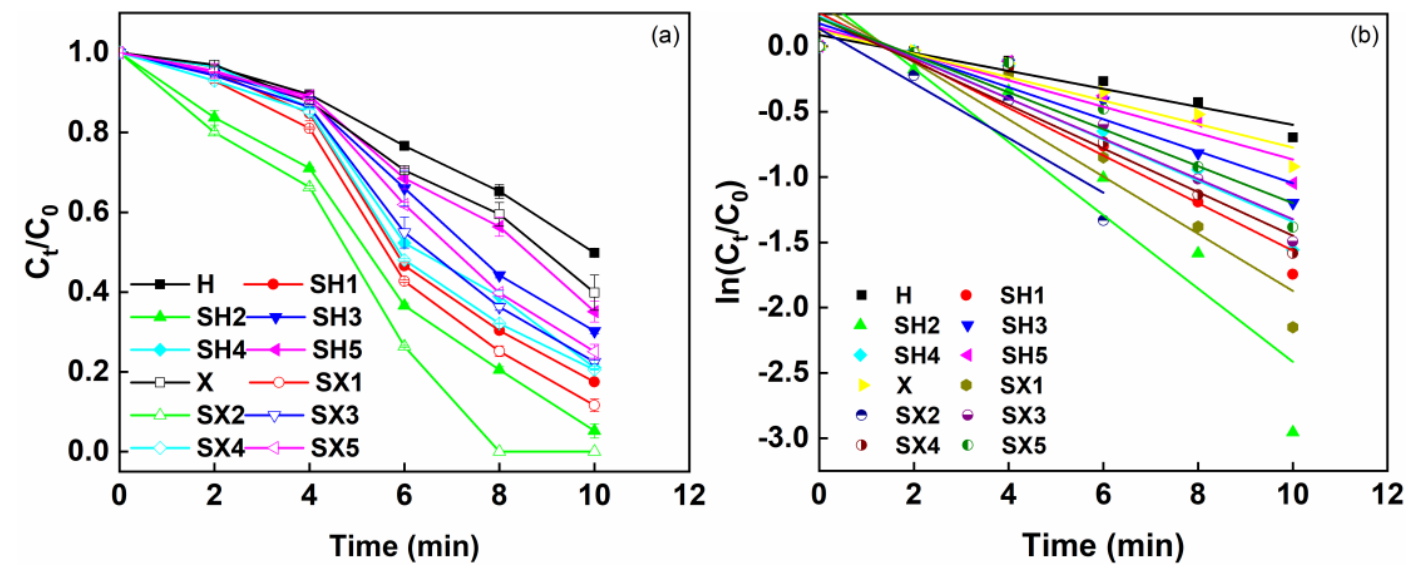

Fig. 4. (a) Spiramycin decay in the presence of pristine and sulfonated biochars under microwave irradiation. (b) Linear curve fitting of the hydrolysis kinetics. Initial spiramycin concentration = $40 \mathrm{mg} / \mathrm{L} ;$ biochar dosage $=1.0 \mathrm{~g} / \mathrm{L} ;$ microwave power $=200 \mathrm{~W}$; reaction time $=10 \mathrm{~min}$; reaction volume $=100 \mathrm{~mL}$ 

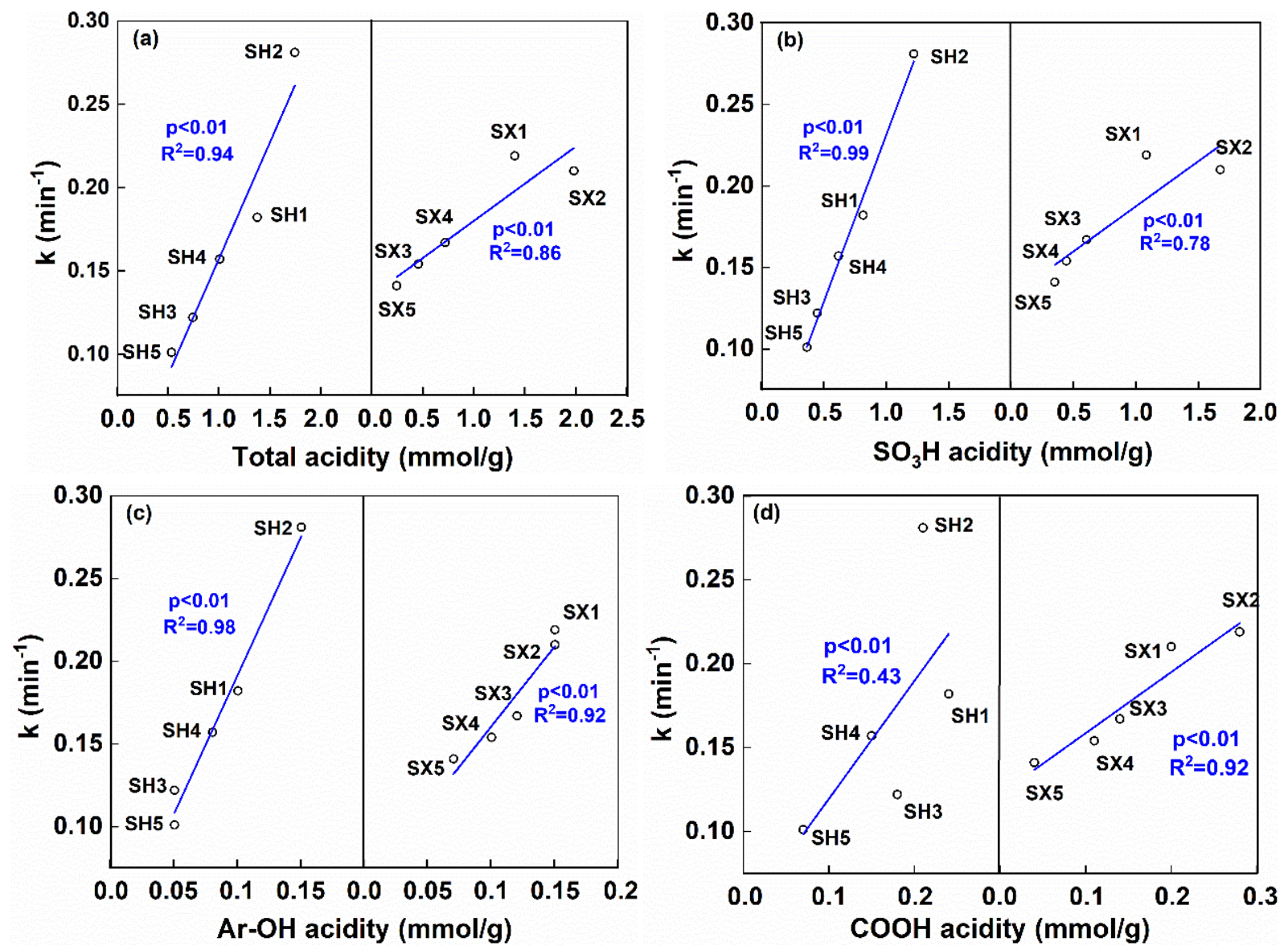

Fig. 5. Relationships between observed kinetic constants of spiramycin hydrolysis and (a) the total acidity, (b) $\mathrm{SO}_{3} \mathrm{H}$ acidity, (c) $\mathrm{Ar}-\mathrm{OH}$ acidity, and (d) $\mathrm{COOH}$ acidity. 

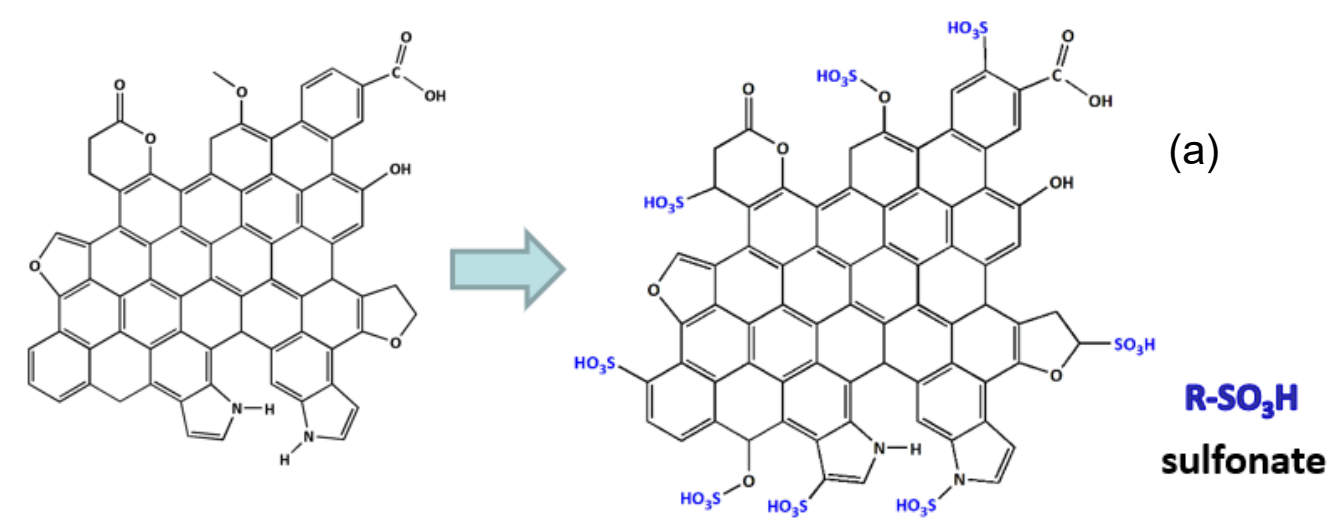

Reaction of O-contained aromatic groups
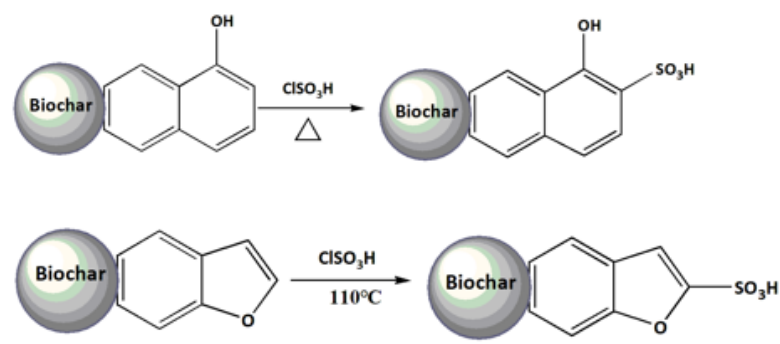<smiles>CC(C)(O)c1[nH]c2cc3c(cc2c1C(=O)O)CCCCC3</smiles>
$\mathrm{N}$-contained aromatic heterocyclic groups

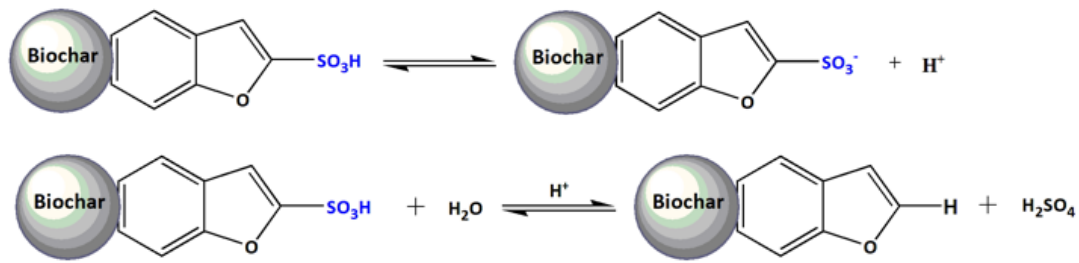

Fig. 6. (a) Schemes for the (a) sulfonation reaction, and (b) deprotonation reaction. 
(a)

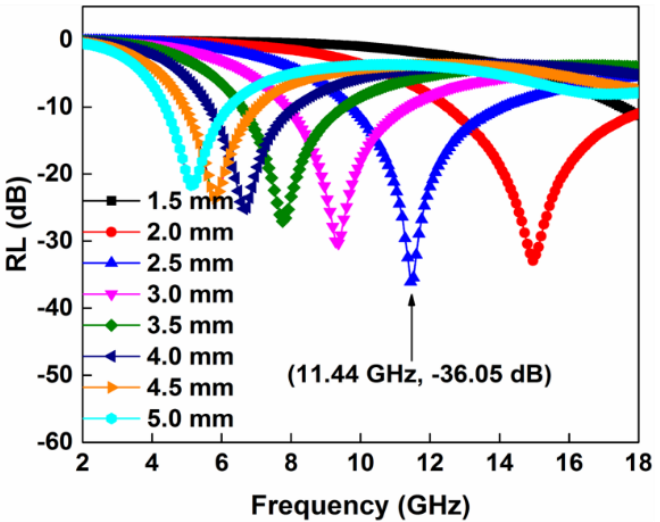

(b)

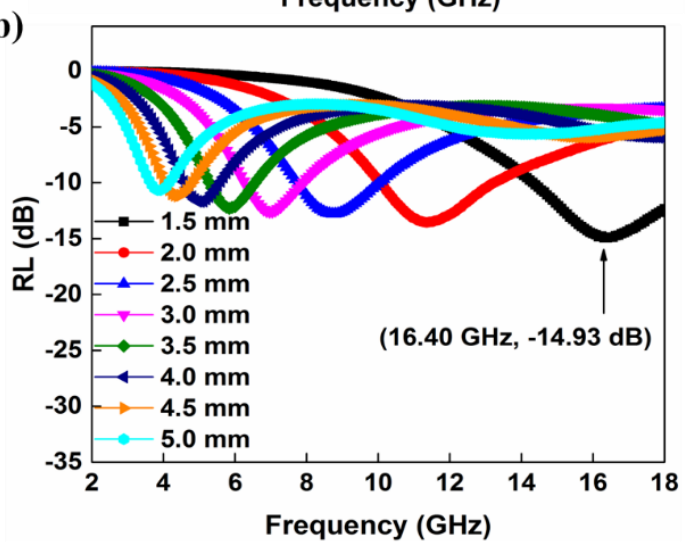

(c)

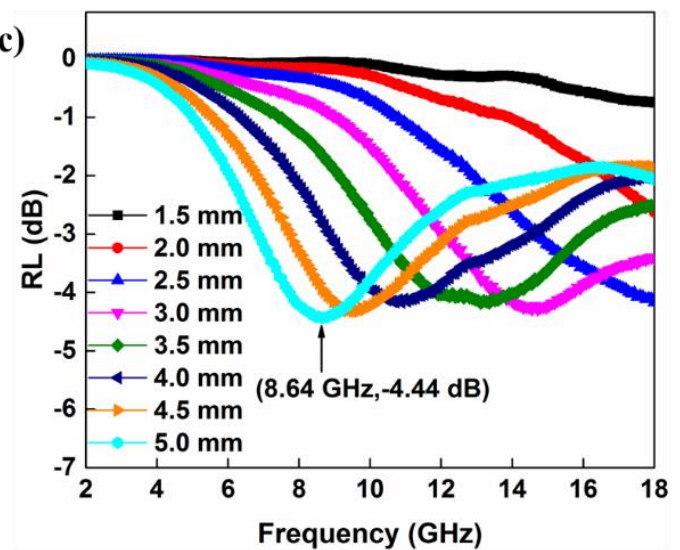

(d)

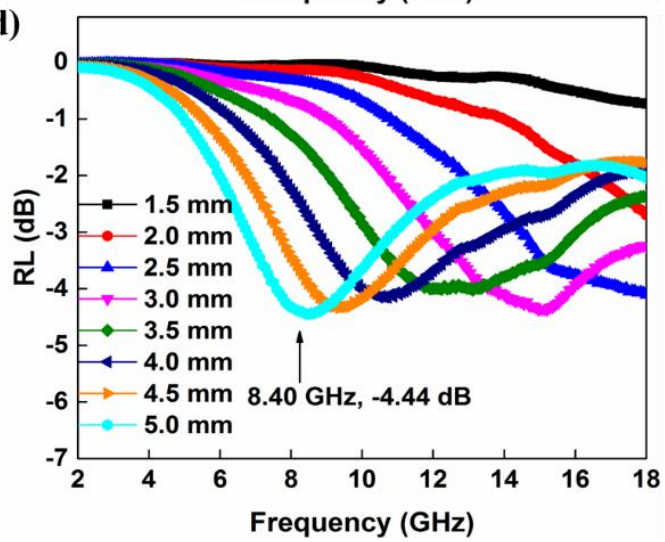

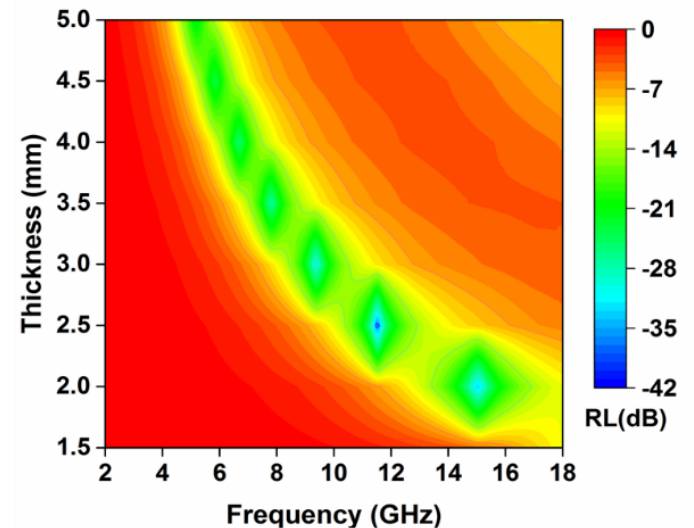
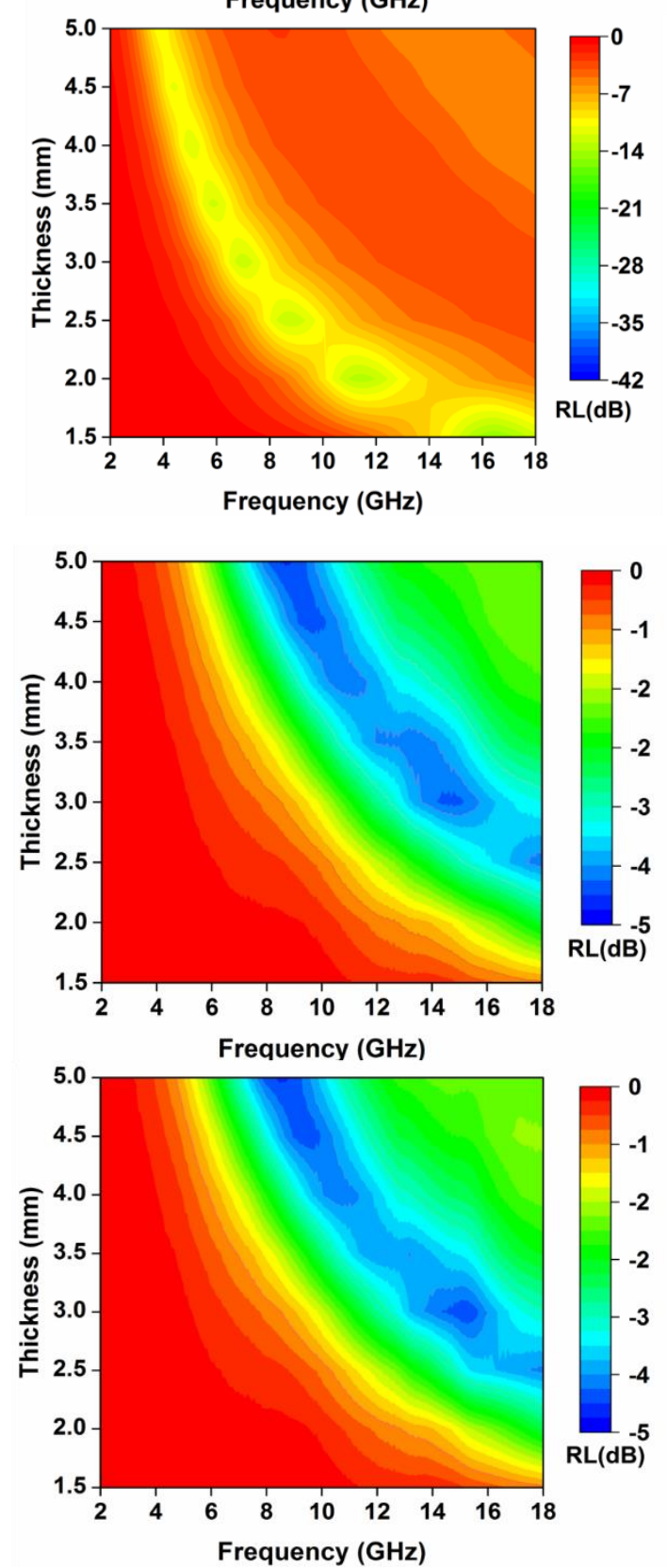

Fig. 7. Relative loss curves of samples in the frequency ( $f$ ) range of $2.0-18.0 \mathrm{GHz}$, and the $2 \mathrm{D}$ contour plots of relative loss against $f$ with different absorber thicknesses: (a) $\mathrm{H}$, (b) $\mathrm{SH} 2$, (c) X 
and (d) SX2. 
Table 1 Sulfonation reagents and reaction conditions employed in the current study.

\begin{tabular}{|c|c|c|c|c|c|c|}
\hline Raw materials & Samples & Reagents & $\begin{array}{l}\text { Solid-liquid ratio or } \\
\text { dosage }\end{array}$ & Conditions & Vessel & Remark \\
\hline \multirow{6}{*}{$\begin{array}{l}\text { Biochar } \\
\text { (Korea) }\end{array}$} & $\mathrm{H}$ & None & None & None & None & Raw material \\
\hline & SH1 & $\mathrm{H}_{2} \mathrm{SO}_{4}$ & $1: 20$ & $100^{\circ} \mathrm{C}, 24 \mathrm{~h}$ & Telfon-lined autoclave & Sulfonated biochar \\
\hline & $\mathrm{SH} 2$ & $\mathrm{ClSO}_{3} \mathrm{H}$ & $1: 20$ & $100^{\circ} \mathrm{C}, 24 \mathrm{~h}$ & Telfon-lined autoclave & Sulfonated biochar \\
\hline & $\mathrm{SH} 3$ & $\mathrm{ClSO}_{3} \mathrm{H}$ & $1: 20$ & $25^{\circ} \mathrm{C}, 24 \mathrm{~h}$ & Beaker & Sulfonated biochar \\
\hline & SH4 & $\mathrm{ClSO}_{3} \mathrm{H}+\mathrm{CHCl}_{3}(\mathrm{v} / \mathrm{v}=1: 1)$ & $\begin{array}{c}\text { 1:20 (corresponding to } \\
20 \mathrm{~mL} \text { of } \mathrm{ClSO}_{3} \mathrm{H} \text { ) }\end{array}$ & $25^{\circ} \mathrm{C}, 24 \mathrm{~h}$ & Beaker & Sulfonated biochar \\
\hline & SH5 & $\mathrm{TsOH}$ & $\begin{array}{c}\text { Equal moles of } \mathrm{SO}_{3} \mathrm{H} \\
\text { in } 20 \mathrm{~mL} \text { of } \mathrm{ClSO}_{3} \mathrm{H} \text {, } \\
53.52 \mathrm{~g} \text { in } 100 \mathrm{~mL} \\
\text { deionized water }\end{array}$ & $100^{\circ} \mathrm{C}, 24 \mathrm{~h}$ & Telfon-lined autoclave & Sulfonated biochar \\
\hline \multirow{5}{*}{$\begin{array}{l}\text { Biochar } \\
\text { (China) }\end{array}$} & $\mathrm{X}$ & None & None & None & None & Raw material \\
\hline & SX1 & $\mathrm{H}_{2} \mathrm{SO}_{4}$ & $1: 20$ & $100^{\circ} \mathrm{C}, 24 \mathrm{~h}$ & Teflon-lined autoclave & Sulfonated biochar \\
\hline & $\mathrm{SX} 2$ & $\mathrm{ClSO}_{3} \mathrm{H}$ & $1: 20$ & $100^{\circ} \mathrm{C}, 24 \mathrm{~h}$ & Telfon-lined autoclave & Sulfonated biochar \\
\hline & SX3 & $\mathrm{ClSO}_{3} \mathrm{H}$ & $1: 20$ & $25^{\circ} \mathrm{C}, 24 \mathrm{~h}$ & Beaker & Sulfonated biochar \\
\hline & SX4 & $\mathrm{ClSO}_{3} \mathrm{H}+\mathrm{CHCl}_{3}(\mathrm{v} / \mathrm{v}=1: 1)$ & $\begin{array}{c}\text { 1:20 (corresponding to } \\
20 \mathrm{~mL} \text { of } \mathrm{ClSO}_{3} \mathrm{H} \text { ) }\end{array}$ & $25^{\circ} \mathrm{C}, 24 \mathrm{~h}$ & Beaker & Sulfonated biochar \\
\hline
\end{tabular}




\section{Equal moles of $\mathrm{SO}_{3} \mathrm{H}$}

SX5

$\mathrm{TsOH}$

in $20 \mathrm{~mL}$ of $\mathrm{ClSO}_{3} \mathrm{H}$,

$53.52 \mathrm{~g}$ in $100 \mathrm{~mL}$

$100{ }^{\circ} \mathrm{C}, 24 \mathrm{~h} \quad$ Telfon-lined autoclave Sulfonated biochar deionized water

Table 2 Ultimate analyses of pristine and sulfonated biochar samples.

\begin{tabular}{|c|c|c|c|c|c|c|c|c|c|}
\hline \multirow{2}{*}{ Samples } & \multicolumn{5}{|c|}{ Elemental analysis results (wt \%) } & \multirow{2}{*}{$\mathrm{H} / \mathrm{C}$} & \multirow{2}{*}{$\mathrm{O} / \mathrm{C}$} & \multirow{2}{*}{$\mathrm{S} / \mathrm{C}$} & \multirow{2}{*}{$(\mathrm{H}+\mathrm{O}) / \mathrm{C}$} \\
\hline & $\mathrm{C}$ & $\mathrm{H}$ & $\mathrm{O}$ & $\mathrm{N}$ & $S$ & & & & \\
\hline $\mathrm{H}$ & 83.39 & 2.08 & 10.80 & 0.34 & 0.55 & 0.30 & 0.10 & 0.01 & 0.40 \\
\hline SH1 & 78.38 & 1.89 & 15.56 & 0.49 & 2.67 & 0.29 & 0.15 & 0.03 & 0.44 \\
\hline $\mathrm{SH} 2$ & 73.04 & 1.84 & 19.90 & 0.39 & 4.12 & 0.30 & 0.20 & 0.06 & 0.51 \\
\hline $\mathrm{SH} 3$ & 81.61 & 2.09 & 12.84 & 0.48 & 1.92 & 0.31 & 0.12 & 0.02 & 0.42 \\
\hline SH4 & 80.50 & 2.01 & 14.29 & 0.41 & 2.05 & 0.30 & 0.13 & 0.03 & 0.43 \\
\hline SH5 & 82.50 & 2.14 & 12.36 & 0.35 & 1.13 & 0.31 & 0.11 & 0.01 & 0.42 \\
\hline$X$ & 78.08 & 2.55 & 17.48 & 1.16 & 0.64 & 0.39 & 0.17 & 0.01 & 0.56 \\
\hline SX1 & 70.37 & 2.30 & 21.74 & 1.26 & 4.13 & 0.39 & 0.23 & 0.06 & 0.62 \\
\hline
\end{tabular}




\begin{tabular}{rrrrrrrrrr} 
SX2 & 65.09 & 2.02 & 25.39 & 1.38 & 6.07 & 0.37 & 0.29 & 0.09 & 0.66 \\
SX3 & 72.36 & 2.45 & 19.72 & 1.19 & 1.85 & 0.41 & 0.20 & 0.03 & 0.61 \\
SX4 & 72.40 & 2.41 & 20.73 & 1.19 & 2.40 & 0.40 & 0.21 & 0.03 & 0.61 \\
SX5 & 74.82 & 2.75 & 18.31 & 1.15 & 1.59 & 0.44 & 0.18 & 0.02 & 0.62 \\
\hline
\end{tabular}




\section{Supplementary materials:}

\section{Conversion of biochar to sulfonated solid acid catalysts for spiramycin}

\section{hydrolysis: Insights into the sulfonation process}

Qianqian Xie ${ }^{1}$, Xiao Yang ${ }^{2}$, Kangning $\mathrm{Xu}^{1}$, Zheng Chen ${ }^{1}$, Binoy Sarkar ${ }^{3}$, Xiaomin $\operatorname{Dou}^{1 *}$

${ }^{1}$ College of Environmental Science and Engineering, Beijing Forestry University, Beijing 100083, P.R. China

${ }^{2}$ Key Laboratory of Land Surface Pattern and Simulation, Institute of Geographic Sciences and Natural Resources Research, Chinese Academy of Sciences, Beijing 100101, China

${ }^{3}$ Lancaster Environment Centre, Lancaster University, Lancaster, LA1 4YQ, United Kingdom

*Corresponding author: Xiaomin Dou (douxiaomin@bjfu.edu.cn)

College of Environmental Science and Engineering, Beijing Forestry University, Beijing 100083, P.R. China 

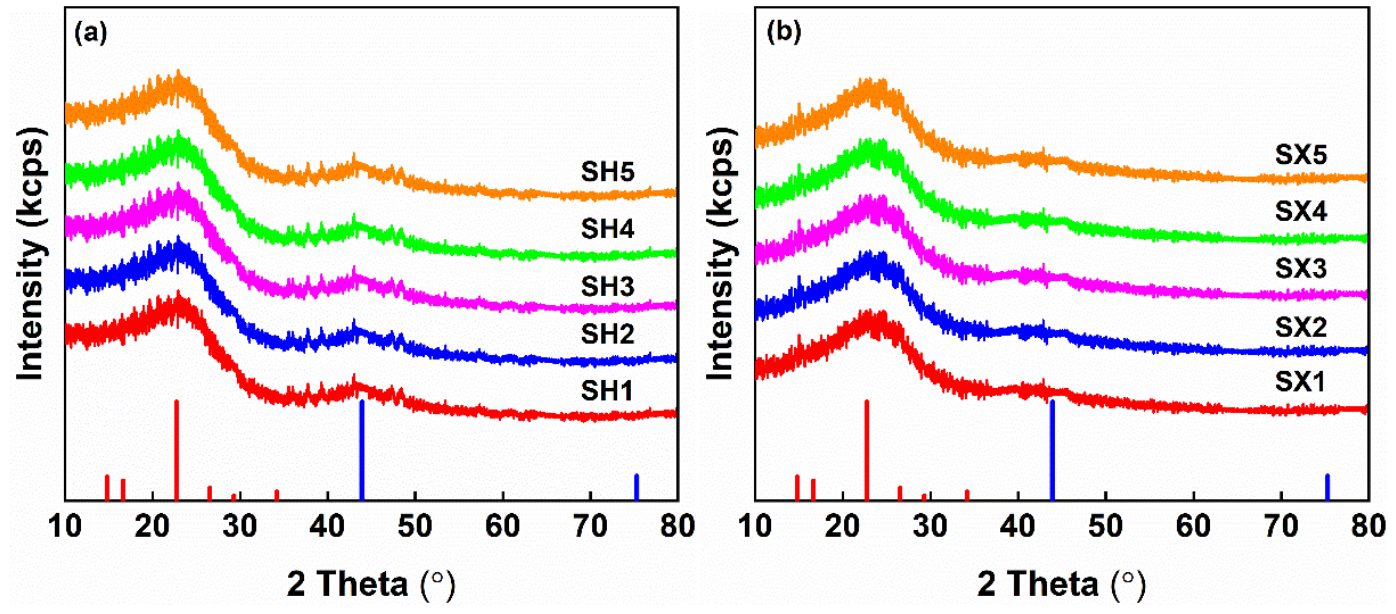

Fig. S1. XRD patterns of the pristine and the sulfonated biochar (a) SH1-SH5 and (b) SX1-SX5.
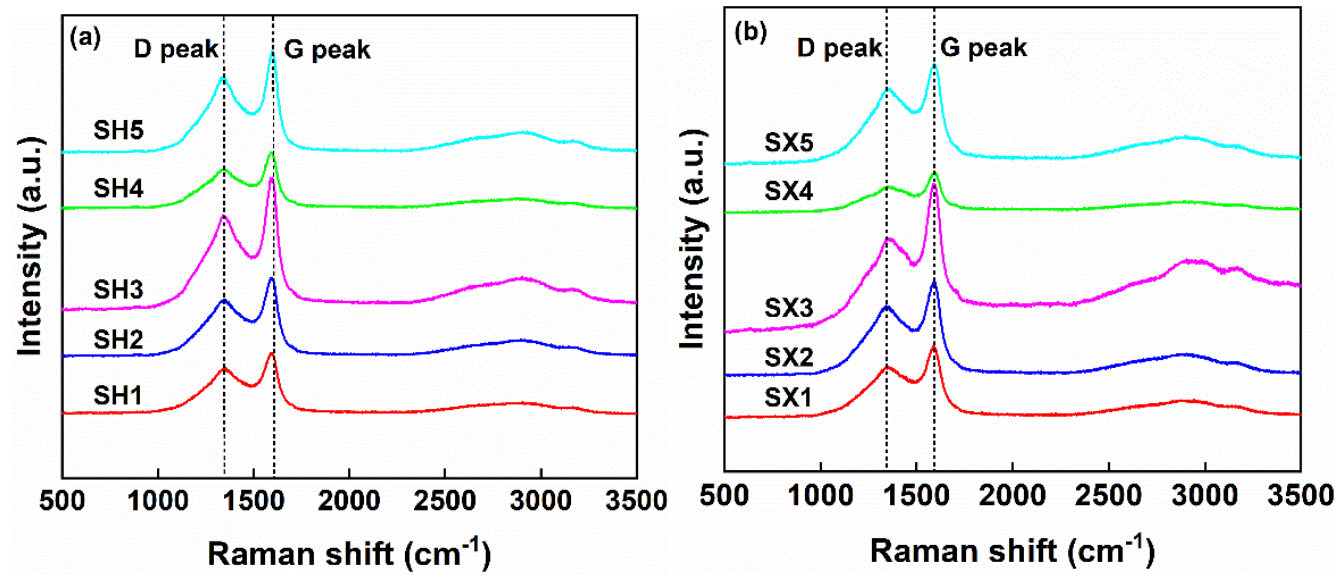

Fig. S2. Raman spectra of the sulfonated biochar (a) SH1-SH5 and (b) SX1-SX5. 

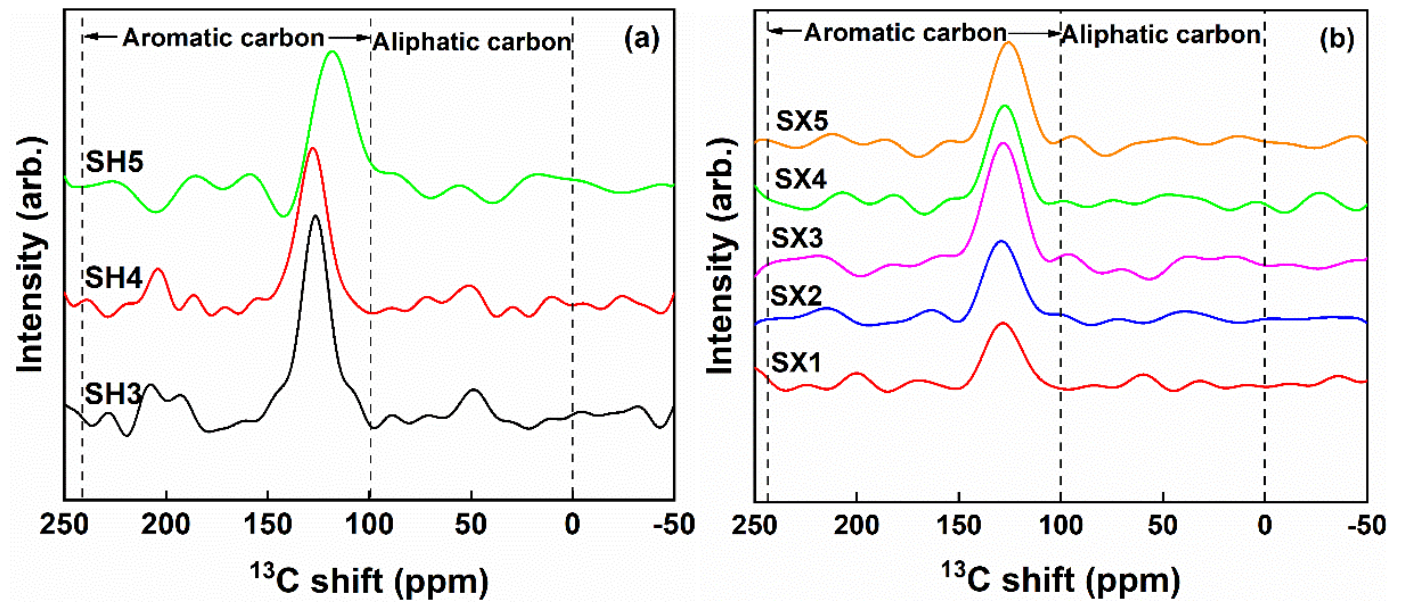

Fig. S3. ${ }^{13} \mathrm{C}$ MAS NMR chemical shifts of the sulfonated biochar (a) SH3-SH5 and (b) SX1-SX5.

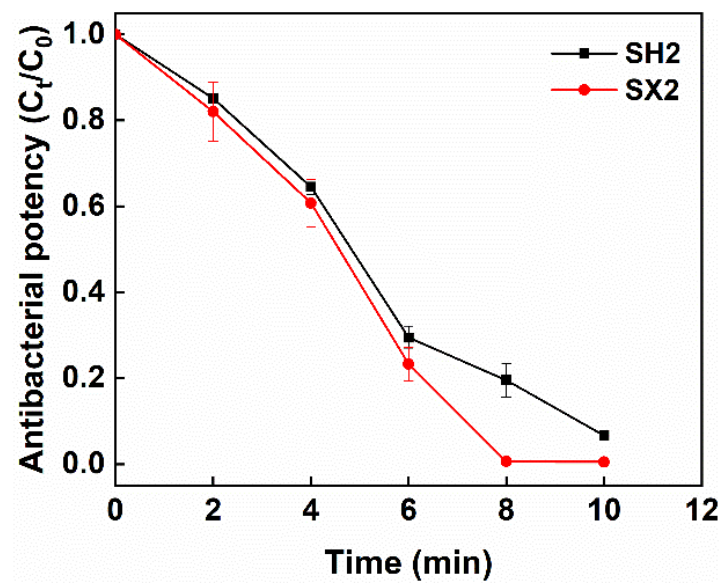

Fig. S4 Decay curves of the antibacterial potency of the hydrolyzed solutions. Initial spiramycin concentration $=40 \mathrm{mg} / \mathrm{L}$; biochar dosage $=1.0 \mathrm{~g} / \mathrm{L}$; microwave power $=200 \mathrm{~W}$; reaction time $=10 \mathrm{~min}$; reaction volume $=100 \mathrm{~mL}$. 
Table S1 Physical properties and acidities of the pristine and sulfonated biochar samples.

\begin{tabular}{ccccccccc}
\hline Biochar & $\begin{array}{c}\text { Surface } \\
\text { area } \\
\text { catalyst }\end{array}$ & $\begin{array}{c}\text { Pore } \\
\text { volume }\end{array}$ & $\begin{array}{c}\text { Pore } \\
\text { diameter }\end{array}$ & $\begin{array}{c}\text { Total } \\
\left(\mathrm{cm}^{3} / \mathrm{g}\right)\end{array}$ & $\begin{array}{c}\mathrm{SO}_{3} \mathrm{H} \\
(\mathrm{nm})\end{array}$ & $\begin{array}{c}\mathrm{COOH} \\
\text { acidity }\end{array}$ & $\begin{array}{c}\text { Ar-OH } \\
\text { acidity } \\
\text { acidity }\end{array}$ & $\begin{array}{c}\text { Lactonic } \\
\text { acidity } \\
(\mathrm{mmol} / \mathrm{g})\end{array}$ \\
\hline $\mathrm{H}$ & 256.33 & 0.14 & 3.15 & 0 & 0 & 0 & 0 & 0 \\
SH1 & 319.13 & 0.17 & 2.90 & 1.05 & 0.61 & 0.24 & 0.1 & 0.1 \\
SH2 & 105.23 & 0.06 & 4.06 & 1.40 & 1.04 & 0.21 & 0.15 & 0 \\
SH3 & 224.60 & 0.13 & 3.68 & 0.45 & 0.22 & 0.18 & 0.05 & 0 \\
SH4 & 190.14 & 0.11 & 18.28 & 0.70 & 0.40 & 0.15 & 0.08 & 0.07 \\
SH5 & 31.20 & 0.02 & 4.31 & 0.25 & 0.13 & 0.07 & 0.05 & 0 \\
X & 16.59 & 0.02 & 5.93 & 0 & 0 & 0 & 0 & 0 \\
SX1 & 289.59 & 0.17 & 3.98 & 1.45 & 1.02 & 0.28 & 0.15 & 0 \\
SX2 & 213.39 & 0.13 & 4.05 & 2.00 & 1.65 & 0.2 & 0.15 & 0 \\
SX3 & 199.39 & 0.36 & 55.61 & 0.55 & 0.34 & 0.11 & 0.1 & 0 \\
SX4 & 38.88 & 0.04 & 4.51 & 0.80 & 0.51 & 0.14 & 0.12 & 0.03 \\
SX5 & 24.85 & 0.03 & 4.96 & 0.35 & 0.24 & 0.04 & 0.07 & 0 \\
\hline
\end{tabular}

